\title{
Stroke and breast cancer in the United States during 2007-2017
}

Irene Rethemiotaki ${ }^{1}$, Andrew Rethemiotakis ${ }^{2}$

\author{
${ }^{1}$ Department of Production Engineering and Management, Technical University \\ of Crete, Chania, Greece \\ ${ }^{2}$ Department of Agriculture, Technological Educational Institute of Crete, Irakllon, \\ Greece
}

Submitted: 5 February 2019

Accepted: 5 May 2019

Arch Med Sci Atheroscler Dis 2019; 4: e134-e140

DOI: https://doi.org/10.5114/amsad.2019.86749

Copyright (c) 2019 Termedia \& Banach

\section{Abstract}

Introduction: The main purpose of this work is to study the malignant neoplasms of the breast and the incidence of strokes in the United States and to find not only statistically significant predictors for cancer, but also a possible association between breast cancer and stroke.

Material and methods: The statistical methods used to derive the results of this work are $\chi^{2}$ and one-way analysis of variance (ANOVA) tests, in order to check the statistical significance of breast cancer in relation to socio-economic factors of patients. In addition, a multivariate logistic regression analysis was used with the odds ratio (OR) to find statistically significant prognostic factors for breast cancer. The Pearson correlation coefficient was used to find the relationship between breast cancer and stroke.

Results: According to multiple logistic regression analysis, widowed women have 11 times higher risk developing breast cancer, while white women who are unemployed but have worked previously have two times higher risk for the occurrence of this type of cancer. In addition, a statistically significant relationship was found between the number of cases of breast cancer and stroke.

Conclusions: Our results describe for the first time the importance of deprivation (of work and partner) as a primary prognostic risk factor for cancer. Moreover, we found a link between breast cancer diagnosis and stroke.

Key words: malignant neoplasms of the breast, prognostic factors, breast cancer, socio-economic factors, stroke.

\section{Introduction}

Breast cancer is the most common malignancy worldwide, accounting for $14 \%$ of all new cancer cases in the world in 2016 [1]. The incidence of breast cancer is mainly observed in women over 40-49 years of age [2]. The main risk factors are age [3], positive family history of cancer [4], early menarche [5] and late childbearing [4, 5], woman's age at menopause [6], and race [7], while in $75-80 \%$ of women no risk factor is found [8]. Regarding the socio-economic factors, increased incidence of breast cancer was found for women with higher education [9-12], highest income [10], and creative core occupation [10,11]. A recent study suggests an association between socio-economic factors and breast cancer and, more specifically, proves that breast cancer tends to be higher across

\author{
Corresponding author: \\ Irene Rethemiotaki \\ Department of Production \\ Engineering \\ and Management \\ Technical University \\ of Crete \\ Chania, Greece \\ E-mail: eirinireth@yahoo.gr
}


richer countries. Women from richer countries are prone to higher demand for treatments represented by oral contraceptives (OCs) and hormone therapy $(\mathrm{HT})$, factors which increase the risk of breast cancer [13].

Prior studies have found increased risk of stroke in patients with breast cancer, who were given radiotherapy (RT). More specifically, it has been found that RT to the supraclavicular lymph nodes gives a significant dose of radiation to the proximal carotid artery, which increases the risk of carotid stenosis and ischaemic stroke [14]. Moreover, cancer is not a well-established independent risk factor for arterial thromboembolism, and cancer patients do not systematically receive treatments to prevent myocardial infarction and stroke, resulting in an increased risk for such cases in cancer patients [15-17].

This work studies breast cancer and stroke in the United States in the years 2007-2017 in order to find statistically significant predictors for cancer and a possible link between breast cancer and stroke.

\section{Material and methods}

The data used in this work come from the National Health Interview Survey dataset [18] and cover the period 2007-2017. The number of breast cancer and stroke patients examined was 37,634 and 71,227, respectively.

\section{Statistical analysis}

The statistical methods used to extract the results of this work are the $\chi^{2}$ test for categorical and one-way analysis of variance (ANOVA) for continuous variables, to check the statistical significance of human breast cancer in relation to selected characteristics of patients such as gender, age, race, origin, education, family income, poverty status, health insurance coverage, place of residence, and region. Factors that determine the prevalence of cancer were assessed by using multiple logistic regression analysis. To better assess the predictors of cancer, we used data from patients with a new diagnosis of cancer compared to a matched cohort of patients without cancer. Predictors were represented using the OR and 95\% confidence intervals, and $p<0.05$ was considered as statistically significant. The Pearson correlation coefficient was used for the relationship between cancer and stroke for the years 2007-2017. The study was carried out using the IBMSPSS 25 software package for Windows.

\section{Results}

To check the zero hypotheses that the mean of the patients in the United States with malignant neoplasms of the breast did not differ according to their socio-economic characteristics, the $\chi^{2}$ test and one-way analysis of variance (ANOVA) were used. As shown in Table I, there is a statistically significant difference in the number of malignant neoplasms of the breast in relation to gender, and it occurs mainly in women (99.4\%). Moreover, the age group with the most frequent occurrence of breast cancer is from 45 to 64 years old (69\%), while the most common origin and race is white (88.9\%), not Hispanic or Latino (48.6\%). The education level that was found to be statistically significant was "less than a high school diploma" (13.2\%). Employment status that was found to be statistically significant was "Not employed but has worked previously" (49.4\%). The financial status that was found to be statistically significant was "not poor", with a family income of $\$ 35,000$ or more (38.6\%). Health insurance coverage was found to be statistically significant in both age groups under 65 years (76.5\%) and 65 years and over (59.5\%) was "private". In addition, the marital status that the most breast cancer patients had was "married" (52.2\%). Finally, the region with the most frequent occurrence of breast cancer was the south (35\%), with a population size of one million or more (51.3\%).

Table II shows the multiple logistic regression analysis and odds ratios in order to find the predictors for the occurrence of breast cancer.

As shown in Table II, all prognostic factors are statistically significant $(p<0.05)$. According to multiple logistic regression, the risk of breast cancer is significantly higher with female gender (odds ratio $(O R)=1.0$ ), age over 75 years and 45-64 years old (OR 1.0 and 0.99, respectively), white race $(O R=1.94)$, and high school diploma education status $(O R=1.2)$. Moreover, those who were unemployed but had worked previously had twice the risk of developing breast cancer (OR = 2.0). In addition, the risk of cancer is significantly higher with family income "\$35,000-\$49,999" $(\mathrm{OR}=1.29)$, poverty status "not poor" $(\mathrm{OR}=1.0)$, and health insurance coverage "Medicaid" under 65 years old and "Private" over 65 years old $(\mathrm{OR}=1.95$ and $\mathrm{OR}=1.27$, respectively $)$. Widowed women had 11 times the risk of developing breast cancer $(O R=11.3)$. Finally, the risk of breast cancer was significantly higher in the region "northeast" $(O R=1.2)$ and place of residence "not in a metropolitan statistical area" (OR = 1.0).

Figure 1 shows the trends in breast cancer and stroke during the years 2007-2017 in the United States. The incidence of breast cancer and stroke continued to increase from 2007 to 2017.

Table III shows the Pearson correlation coefficient among the total number of breast cancer and stroke patients for the years 2007-2017. As can be seen from Table III, the incidence of cancer is 
Table I. $\chi^{2}$ and one-way analysis of variance (ANOVA) test

\begin{tabular}{|c|c|c|c|}
\hline $\begin{array}{l}\text { Selected characteristics of breast cancer patients: United States } \\
2007-2017\end{array}$ & $\begin{array}{l}\text { Number } \\
\text { of patients }\end{array}$ & Percentages & $P$-value \\
\hline Gender: & 37.634 & & $<0.001$ \\
\hline Male & 256 & 0.6 & \\
\hline Female & 37.378 & 99.4 & \\
\hline Age: & & & $<0.001$ \\
\hline $18-44$ & 1.651 & 2.5 & \\
\hline $45-64$ & 14.569 & 69.0 & \\
\hline $65-74$ & 10.320 & 13.5 & \\
\hline 75 and over & 11.194 & 14.9 & \\
\hline Race: & & & $<0.001$ \\
\hline White & 32.645 & 88.9 & \\
\hline Black or African American & 3.107 & 8.1 & \\
\hline Asian & 1.223 & 3.0 & \\
\hline Origin: & & & $<0.001$ \\
\hline Hispanic or Latino & 2.485 & 3.3 & \\
\hline Mexican or Mexican American & 1.479 & 1.9 & \\
\hline Not Hispanic or Latino & 35.246 & 48.6 & \\
\hline White, single race & 30.440 & 42.2 & \\
\hline Black or African American, single race & 2.996 & 4.0 & \\
\hline Education: & & & $<0.001$ \\
\hline Less than a high school diploma & 4.872 & 13.2 & \\
\hline High school diploma & 5.526 & 29.5 & \\
\hline Some college & 10.512 & 27.9 & \\
\hline Bachelor's degree or higher & 11.061 & 29.4 & \\
\hline \multicolumn{4}{|l|}{ Employment: } \\
\hline Employed & 6.804 & 23.4 & $<0.001$ \\
\hline Full-time & 4.888 & 16.9 & \\
\hline Part-time & 1.724 & 6.0 & \\
\hline Not employed but has worked previously & 2.378 & 49.4 & \\
\hline Not employed and has never worked & 1.193 & 4.3 & \\
\hline Family income: & & & $<0.001$ \\
\hline Less than $\$ 35,000$ & 12.308 & 22.9 & \\
\hline$\$ 35,000$ or more & 20.877 & 38.6 & \\
\hline$\$ 35,000-\$ 49,999$ & 5.045 & 9.6 & \\
\hline$\$ 50,000-\$ 74,999$ & 5.424 & 10.1 & \\
\hline$\$ 75,000-\$ 99,999$ & 3.571 & 6.6 & \\
\hline$\$ 100,000$ or more & 6.838 & 12.3 & \\
\hline
\end{tabular}


Table I. Cont.

\begin{tabular}{|c|c|c|c|}
\hline $\begin{array}{l}\text { Selected characteristics of breast cancer patients: United States } \\
2007-2017\end{array}$ & $\begin{array}{l}\text { Number } \\
\text { of patients }\end{array}$ & Percentages & $P$-value \\
\hline Poverty status: & & & $<0.001$ \\
\hline Poor & 2.940 & 8.7 & \\
\hline Near poor & 5.702 & 17.0 & \\
\hline Not poor & 24.906 & 74.4 & \\
\hline \multicolumn{4}{|l|}{ Health insurance coverage: } \\
\hline Under 65: & & & $<0.001$ \\
\hline Private & 12.305 & 76.5 & \\
\hline Medicaid & 2.070 & 12.8 & \\
\hline Other coverage & 840 & 5.0 & \\
\hline Uninsured & 917 & 5.7 & \\
\hline 65 and over: & & & 0.001 \\
\hline Private & 16.174 & 59.5 & \\
\hline Medicare and Medicaid & 1.663 & 6.1 & \\
\hline Medicare only & 7.474 & 28.3 & \\
\hline Other coverage & 1.662 & 6.1 & \\
\hline Marital status: & & & $<0.001$ \\
\hline Married & 19.851 & 52.2 & \\
\hline Widowed & 9.055 & 24.5 & \\
\hline Divorced or separated & 5.726 & 15.4 & \\
\hline Never married & 1.966 & 5.1 & \\
\hline Living with a partner & 1.042 & 2.7 & \\
\hline Place of residence (metropolitan statistical area - MSA): & & & $<0.001$ \\
\hline Large MSA (population size 1 million or more) & 19.516 & 51.3 & \\
\hline Small MSA (less than 1 million) & 11.388 & 30.3 & \\
\hline Not in MSA & 6.830 & 18.4 & \\
\hline Region: & & & $<0.001$ \\
\hline Northeast & 7.290 & 18.9 & \\
\hline Midwest & 9.065 & 24.1 & \\
\hline South & 13.164 & 35.0 & \\
\hline West & 8.214 & 21.9 & \\
\hline
\end{tabular}

statistically significant with stroke $(p<0.05)$. The Pearson correlation coefficient between the total number of cancer patients and stroke patients is 0.872 , which indicates that there is a strong correlation between breast cancer and stroke.

\section{Discussion}

Increasing attention should be given to the increasing number of breast cancer patients in the
United States during the years 2007-2017. It has been noted that the characteristic of patients with the highest risk is their marital status, and more specifically, it was found that widowed women have 11 times higher risk of developing breast cancer $(\mathrm{OR}=11.3)$. Moreover, employment status plays a crucial role in developing this type of cancer. Women who were unemployed but had worked previously had twice the risk of develop- 
Table II. Statistically significant predictors of breast cancer in US using multivariate logistic regression

\begin{tabular}{|c|c|c|c|c|}
\hline $\begin{array}{l}\text { Socio-economic characteristics of breast cancer } \\
\text { patients: } 2007-2017\end{array}$ & Patients & Controls & Odds ratio $(95 \% \mathrm{Cl})$ & $P$-value \\
\hline Gender: & & & & $<0.001$ \\
\hline Male & 200 & 1.127.215 & $0.07(0.05-0.07)$ & \\
\hline Female & 33.477 & 2.305 .890 & 1.0 (ref.) & \\
\hline Age: & & & & $<0.001$ \\
\hline $18-44$ & 1.470 & 1112863 & $0.025(0.024-0.027)$ & \\
\hline $45-64$ & 13.099 & 794485 & $0.99(0.96-1.0)$ & \\
\hline $65-74$ & 9.130 & 224824 & $0.68(0.6-0.7)$ & \\
\hline 75 and over & 10.077 & 170.360 & 1.0 (ref.) & \\
\hline Race: & & & & $<0.001$ \\
\hline White & 29.404 & 1.841 .244 & 1.94 & \\
\hline Black or African American & 2.688 & 278.992 & 1.17 & \\
\hline Asian & 999 & 121.990 & 1.0 (ref.) & \\
\hline Origin: & & & & 0.000 \\
\hline Hispanic or Latino & 2.133 & 338.233 & $0.64(0.6-0.68)$ & \\
\hline Mexican or Mexican American & 1.251 & 208.223 & $0.61(0.57-0.65)$ & \\
\hline Not Hispanic or Latino & 31.640 & 1.964 .300 & $1.64(1.5-1.7)$ & \\
\hline White, single race & 27.449 & 1.533 .489 & $1.82(1.7-1.9)$ & \\
\hline Black or African American, single race & 2.624 & 267.881 & 1.0 (ref.) & \\
\hline Education: & & & & $<0.001$ \\
\hline Less than a high school diploma & 4.416 & 276.082 & $1.01(0.9-1.0)$ & \\
\hline High school diploma & 9.894 & 520.095 & $1.20(1.17-1.24)$ & \\
\hline Some college & 9.370 & 571.173 & $1.04(1.01-1.07)$ & \\
\hline Bachelor's degree or higher & 9.871 & 626.702 & 1.0 (ref.) & \\
\hline Employment: & & & & $<0.001$ \\
\hline Employed & 5.548 & 727.135 & $0.5(0.4-0.53)$ & \\
\hline Full-time & 4.008 & 586.800 & $0.45(0.42-0.48)$ & \\
\hline Part-time & 1.433 & 129.836 & $0.72(0.67-0.79)$ & \\
\hline Not employed but has worked previously & 11.740 & 386.217 & $2.0(1.8-2.1)$ & \\
\hline Not employed and has never worked & 1.017 & 67.103 & 1.0 (ref.) & \\
\hline Family income: & & & & $<0.001$ \\
\hline Less than $\$ 35,000$ & 11.094 & 695.245 & $1.3(1.2-1.34)$ & \\
\hline$\$ 35,000$ or more & 18.716 & 1.419 .425 & $1.07(1.04-1.1)$ & \\
\hline$\$ 35,000-\$ 49,999$ & 4.639 & 291.260 & $1.29(1.2-1.34)$ & \\
\hline$\$ 50,000-\$ 74,999$ & 4.923 & 380.211 & $1.05(1.01-1.09)$ & \\
\hline$\$ 75,000-\$ 99,999$ & 3.184 & 262.244 & $0.98(0.94-1.0)$ & \\
\hline$\$ 100,000$ or more & 5.971 & 485.707 & 1.0 (ref.) & \\
\hline
\end{tabular}


Table II. Cont.

\begin{tabular}{|c|c|c|c|c|}
\hline $\begin{array}{l}\text { Socio-economic characteristics of breast cancer } \\
\text { patients: } 2007-2017\end{array}$ & Patients & Controls & Odds ratio $(95 \% \mathrm{Cl})$ & $P$-value \\
\hline Poverty status: & & & & $<0.001$ \\
\hline Poor & 2.598 & 277.817 & $0.61(0.59-0.64)$ & \\
\hline Near poor & 5.068 & 369.495 & $0.90(0.88-0.93)$ & \\
\hline Not poor & 22.221 & 1.470 .210 & 1.0 (ref.) & \\
\hline Health insurance coverage: & & & & $<0.001$ \\
\hline \multicolumn{5}{|l|}{ Under 65: } \\
\hline Private & 11.073 & 1.265 .457 & $3.69(3.4-3.9)$ & \\
\hline Medicaid & 1.856 & 198.207 & $3.95(3.6-4.2)$ & \\
\hline Other coverage & 721 & 83.015 & $3.66(3.3-4.0)$ & \\
\hline Uninsured & 831 & 351.007 & 1.0 (ref.) & \\
\hline 65 and over: & & & & $<0.001$ \\
\hline Private & 15.032 & 195.568 & $1.27(1.2-1.3)$ & \\
\hline Medicare and Medicaid & 1.538 & 26.007 & $0.98(0.91-1.0)$ & \\
\hline Medicare only & 7.141 & 99.370 & $1.19(1.12-1.26)$ & \\
\hline Other coverage & 1.535 & 25.478 & 1.0 (ref.) & \\
\hline Marital status: & & & & $<0.001$ \\
\hline Married & 17.596 & 1.236 .918 & $2.5(2.4-2.7)$ & \\
\hline Widowed & 8.257 & 132.025 & $11.3(10.6-12.1)$ & \\
\hline Divorced or separated & 5.202 & 258.718 & $3.6(3.4-3.9)$ & \\
\hline Never married & 1.716 & 505.169 & $0.6(0.57-0.67)$ & \\
\hline Living with a partner & 911 & 165.756 & 1.0 (ref.) & \\
\hline Place of residence (metropolitan statistical area - MSA): & & & & $<0.001$ \\
\hline Large MSA (population size 1 million or more) & 17.321 & 1.223 .889 & $0.81(0.79-084)$ & \\
\hline Small MSA (less than 1 million) & 10.247 & 719.703 & $0.82(0.79-0.85)$ & \\
\hline Not in MSA & 6.208 & 358.941 & 1.0 (ref.) & \\
\hline Region: & & & & $<0.001$ \\
\hline Northeast & 6.400 & 405.297 & $1.12(1.0-1.1)$ & \\
\hline Midwest & 8.142 & 532.672 & $1.09(1.05-1.1)$ & \\
\hline South & 11.831 & 836.763 & $1.0(0.9-1.03)$ & \\
\hline West & 7.402 & 527.800 & 1.0 (ref.) & \\
\hline
\end{tabular}

ing breast cancer $(O R=2.0)$. Finally, white race is a prognostic risk for this type of cancer; it was found that white women in the U.S. have two times higher risk of developing breast cancer $(\mathrm{OR}=1.94)$.

The importance of this study lies in the association of multiple socio-economic variables with cancer, which reflects the complexity and multidimensional nature of deprivation as well as the various roles of these dimensions throughout life, which in turn reflects the longest gestation period for cancer. More specifically, we found that partner and work deprivation were two determinants in an adult's life, which rapidly increased the risk of cancer. We also found that not only deprivation but also the death of a partner plays a key role in the increased risk of developing cancer.

Moreover, we found a link between breast cancer diagnosis and stroke. One possible explana- 


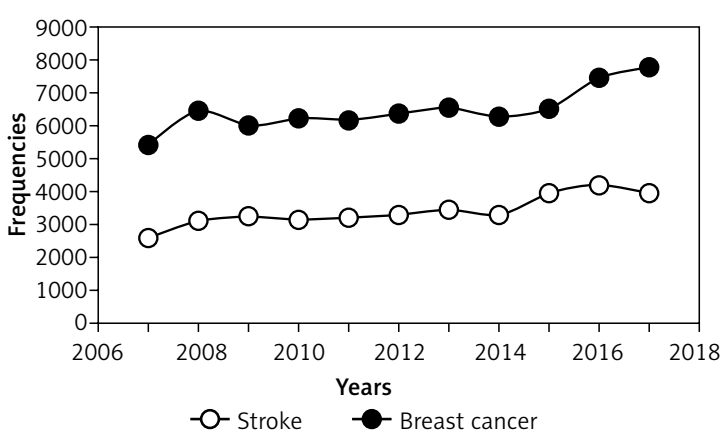

Figure 1. Trends in breast cancer and stroke during the years 2007-2017 in the United States

Table III. Pearson correlation coefficient

\begin{tabular}{|lcc|}
\hline Variable & Pearson correlation $r$ & $P$-value \\
\hline Breast cancer & 1 & \\
\hline Stroke & 0.872 & $<0.01$ \\
\hline
\end{tabular}

tion is that cancer can cause a hypercoagulable state through circulating microparticles, secretion of proliferative factors, and alterations in platelet activity and endothelial function [19, 20]. Additionally, several cancer treatments, particularly platinum-based compounds, may increase thrombotic risk $[19,21]$.

In conclusion, this paper has highlighted that different socioeconomic variables are associated with different cancer risks, while deprivation (of work and husband) proved to be the primary prognostic risk factor for cancer. Moreover, incident cancer is associated with an increased risk of stroke.

\section{Conflict of interest}

The authors declare no conflict of interest.

\section{References}

1. Kispert S, McHowat J. Recent insights into cigarette smoking as a lifestyle risk factor for breast cancer. Breast Cancer 2017; 9: 127-32.

2. Shoemaker ML, White MC, Wu M, et al. Differences in breast cancer incidence among young women aged 2049 years by stage and tumor characteristics, age, race, and ethnicity, 2004-2013. Breast Cancer Res Treat 2018; 169: 595-606.

3. Chen HL, Zhou MQ, Tian W, Meng KX, He HF. Effect of age on breast cancer patient prognoses: a population-based study using the SEER 18 database. PLoS One 2016; 11: e0165409.

4. Petracci E, Decarli A, Schairer C, et al. Risk factor modification and projections of absolute breast cancer risk. J Natl Cancer Inst 2011; 103: 1037-48.

5. Villeneuve S, Fevotte J, Anger A, et al. Breast cancer risk by occupation and industry: analysis of the CECILE study, a population-based case-control study in France. Am J Ind Med 2011; 54: 499-509.

6. Collaborative Group on Hormonal Factors in Breast Cancer. Menarche, menopause, and breast cancer risk: individual participant meta-analysis, including 118964 women with breast cancer from 117 epidemiological studies. Lancet Oncol 2012; 13: 1141-51.

7. Maskarinec G, Sen C, Koga K, Conroy SM. Ethnic differences in breast cancer survival: status and determinants. Womens Health (Lond) 2011; 7: 677-87.

8. Bucholc M, Lepecka-Klusek C, Pilewska A, et al. Ryzyko zachorowania na raka piersi w opinii kobiet. Ginekol Pol 2001; 72: 1460-56

9. Beiki O, Hall P, Ekbom A, Moradi T. Breast cancer incidence and case fatality among 4.7 million women in relation to social and ethnic background: a populationbased cohort study. Breast Cancer Res 2012; 14: R5.

10. Carlsen K, Hoybye MT, Dalton SO, Tjonneland A. Social inequality and incidence of and survival from breast cancer in a population-based study in Denmark, 19942003. Eur J Cancer 2008; 44: 1996-2002.

11. Larsen SB, Olsen A, Lynch J, et al. Socioeconomic position and lifestyle in relation to breast cancer incidence among postmenopausal women: a prospective cohort study, Denmark, 1993-2006. Cancer Epidemiol 2011; 35: 438-41.

12. Vidarsdottir H, Gunnarsdottir HK, Olafsdottir EJ, et al. Cancer risk by education in Iceland; a census-based cohort study. Acta Oncol 2008; 47: 385-90.

13. Chagpar A, Coccia M. Breast cancer and socio-economic factors. Working Paper of Public Health, n. 7. Alessandria (Italy): Azienda Ospedaliera SS. Antonio e Biagio Arrigo; 2012.

14. Nilsson G, Holmberg L, Garmo H, Terent A, Blomqvist C. Increased incidence of stroke in women with breast cancer. Eur J Cancer 2005; 41: 423-9.

15. Goff DC, Lloyd-Jones DM, Bennett G, et al. ACC/AHA guideline on the assessment of cardiovascular risk. J Am Coll Cardiol 2014; 63: 2935-59.

16. Meschia JF, Bushnell C, Boden-Albala B, et al.; American Heart Association Stroke Council; Council on Cardiovascular and Stroke Nursing; Council on Clinical Cardiology; Council on Functional Genomics and Translational Biology; Council on Hypertension. Guidelines for the primary prevention of stroke: a statement for healthcare professionals from the American Heart Association/American Stroke Association. Stroke 2014; 45: 3754-832.

17. McSweeney JC, Rosenfeld AG, Abel WM, et al.; American Heart Association Council on Cardiovascular and Stroke Nursing, Council on Clinical Cardiology, Council on Epidemiology and Prevention, Council on Hypertension, Council on Lifestyle and Cardiometabolic Health, and Council on Quality of Care and Outcomes Research. Preventing and experiencing ischemic heart disease as a woman: state of the science: a scientific statement from the American Heart Association. Circulation 2016; 133: 1302-31.

18. National Center for Health Statistics. Data file documentation, National Health Interview Survey, 2016. Available from: https://www.cdc.gov/nchs/nhis.htm.

19. Gomes M, Khorana AA. Risk assessment for thrombosis in cancer. Semin Thromb Hemost 2014; 40: 319-24.

20. Bick RL. Cancer-associated thrombosis. N Engl J Med 2003; 349: 109-11.

21. Li SH, Chen WH, Tang Y, et al. Incidence of ischemic stroke post-chemotherapy: a retrospective review of 10,963 patients. Clin Neurol Neurosurg 2006; 108: 150-6. 